\title{
Research of the impact of aesthetic psychology on graphic design
}

\author{
Jing XIAO \\ Art Institute \\ Jiujiang University \\ Jiujiang, 332000,China
}

\begin{abstract}
In the contemporary design scene, the design vocabulary from different historical periods and different countries begin to appear with a wide range of forms in front of us, so that our national and traditional design history and vocabulary resources exposure to a diversified design scene. We did see the worldwide spread of an international style, and we also saw that the ego, ethnic and national cultural identity of design is also constantly highlighted in the globalized economy and cultural scene, so it is a thought-provoking question that how to think about their own cultural identity design in the global and diversified scene, how to create design products that have national design features in a globalized scenario, and reflect their own national aesthetic trends.
\end{abstract}

Keywords- aesthetic psychology; graphic design; impact

\section{INTRODUCTION}

Plekhanov once said: 'Any nation's art is determined by its psychological; its psychology is caused by its situation, and the situation in the final analysis is restricted by its productive forces and its relations of production constraints.' However, the psychological quality of the nation including difference in their aesthetic psychology, is influenced by many factors in addition that the development of the productive forces and relations of production are at different stages, which can be divided into natural and social systems. Natural system mainly refers to specific geographic, climatic conditions, and psychological characteristics of the race formed. People always live in a certain area, and according to the qualitative analysis of philosophy reflect theory and art sociological theory, it is convinced that the special nature of the geographical environment has an obvious role on the formation of aesthetic psychology. "Environmental determinism" advocated by Montesquieu, Mrs. Michael F. Starr, Dana and others emphasizes the decisive role of natural conditions outside to the national spirit. Ancient Greek historian Herodotus believed all historical research must consider the particular geographical environment, and regarded the geographical environment as the natural background and stage of development of national history and culture, and historical facts only makes sense when they are contacted with geographical perspective. Aristotle also believed while a certain area can fit for human's habitation has great relations with different latitudes. He founded the environmental geography and believed that geographical environment is both physical environment for human survival and the relationship system restricting the social existence, and absorbs the geographical environment into the ambit of human history and culture investigation.

The famous esthetician, art historian Danner regarded the race, environment and the era as the three elements to decide the national spirits, and the analysis of his "art philosophy" of the relationship between different ethnic and geographical conditions and the development of the national art, can still give us a lot of inspiration.

In short, no matter what kind of form of religion, had a special role to people's aesthetic activities because of its special place in the life of the human spirits. At the same time, because this effect is broad and profound and experienced a long history of formation, it has a special significance on the development of aesthetic psychology. Besides, some forms of social existence having both the dual nature of certain material culture and spiritual culture such as the national unique lifestyle and behavior, and links and ties between 'inner sense' social consciousness and 'external' material, such as the nation's customs, etc. also has a special significance on creating psychological structure of the nation and reflecting the aesthetic taste and aesthetic ideal of the nation.

After thousands of years, different nationalities, different historical and geographical environment precipitated different cultures. Different cultures contain different aesthetic taste, aesthetic ideal, aesthetic pursuit. For example, the Japanese like the quiet, harmonious, gray tone beauty; Frenchman like romantic art; Italians like warm and imaginative design; Americans like commercial design and digital or science fiction experience and so on.

After a long process of historical development, each nation formed their own ideas, thinking and traditional culture, which inevitably plays an important and irresistible role to people's awareness and behavioral activity in reality, and has impact on the national aesthetic activities and creates traditional aesthetic characteristics at the same time, and reflects the aesthetic ideal, aesthetic taste, aesthetic criteria and aesthetic emotions of the people.

\section{THE SUMMARY OF GRAPHIC DESIGN}

Graphic design is the creative design showed in the twodimensional plane. It relates to all aspects of life and has 
made a great contribution to improving our quality of life. Graphic design is different from the pure art, and it is a combination of market and art rather than a pure art form. Graphic design has purpose from the outset, and thinks with the purpose. On the base of purpose, the existence of the various elements is consistent with the purpose. It is the result of rational thinking and the combination of practice and art. It focused on the pursuit of the perfect form and emotional expression on the basis of practice, giving works as much as possible the value of works of art and aesthetics, and good design is to find the balance point in the resulting practical and designer's heart. Graphic design, painting, photography and calligraphy have close relations, because it is the creation of a two-dimensional plane and it has strong implement ability, and less external restrictions. Therefore, in the many design species, graphic design is the one having a tighter link with art and it is the design category mostly influenced by the modernist painting. Whether it is in the form, content and mode, modernist painting has a profound impact on graphic design (It should be noted that graphic design discussed in this article do not refer to "a face" from ancient times in all creation, but to the product leaded by European industrial revolution of the 19th century.).

Impressionism emerged in the second half of the 19th century is a transition from traditional to modern form, whose theme is light and color. Painting steered from the original body study to color study, which created the foundation for the modern color design. Hybrid in constituting the space plane is to inherit and carry forward stippling school, in which recognizing colors and do toning exercises laid a foundation for the application of point and color. Post-Impressionism focus on the use of color and line and generally speaking this stage guides the applications of point, line and color of graphic design. Having got this stage, drawing has dramatic changes compared with the past, but the impact on modern graphic design that we are going to explore is not obvious. What have impact on graphic design and play a direct role in promoting should be Cubism and Futurism, Dadaism, Surrealism, De Stijl, pop art and some other modern genres. These art schools not only play a profound impact on the form of the performance of the graphic design, but also guide its development from the thinking mode.

\section{AESTHETIC TRENDS FROM CONTEMPORARY VISUAL CULTURE TO GRAPHIC DESIGN}

In the changes in the visual presentation, both threedimensional video-based design and two-dimensional spacebased graphic design are faced with new developments and opportunities. As important aspects of a visual communication art design, graphic design reflects the characteristics of the times and the rich connotation.

From the technical perspective before the 15 th century to the development of electronic technology from the 1960s, graphic design has gone through different stages of development, with the development of science and technology and the use of a variety of techniques, bringing a different effect of visual experience. In contemporary culture, the image has become a ubiquitous presence. Professor Zhou
Xian believes that modern people are going through the new culture law of "Reading Pictures", and the image of the visual attention of the eye forms a unique economy. In other words, we are experiencing an era of so-called "graphic war", namely the cognitive challenge to the traditional culture of the text coming from advertising poster design, book design, CI design, packaging design and other graphic design. And how can people resonate in a variety of communication and exchange of graphic design in the constitution of a hegemonic aesthetic chain with hegemonic image? The study found that, in all kinds of image endorsement, fast movingconsumer goods and environmental placard poster public service ads, it is all emphasized a "preconceived" visual communication experience. Especially when multimedia technology, digital technology is widely used in graphic design, graphic design itself is attracting people's attention by a combination of a variety of video, variation, virtual. Experience passed by visual images plane is no longer seek agreement with the relevant images in their expression in real life, and the content is important, but the form is the first, and the screen tends to reshape people's visual experience.

We might look at this that aesthetic trends of contemporary visual graphic design firstly broke the visual expression that regards the product itself as the demands under the traditional concepts. In an era dominated by eyeball economy, we believe that "looking that is consumption", and the visual consumption gradually have a place in consumer attitudes. In today's consumer attitudes, we no longer the exclude visual enjoy and people's pursuit for the visual is also to meet people's need. First, contemporary visual aesthetic tends to provide people with pleasure, sensual and ephemeral aesthetic experience. For example, in a lot of the plane posters of beautiful cover and the rhetoric of beautiful girl, Professor Zhou Xian said: "Cover Girl fetishism is not only worship for a specific image or personal, but worship for commodity and the value, and cover girl photos possess some technical and formal perfection, which constitute a strong visual appeal. As a form of visual culture shaped by, cover girl image's mysterious function is not that the real figure is closer to photograph, but on the contrary, is that the face of varying different characters are closer to their idealized cover girl image and its program and sets . "

As the saying goes, the performance of change in cover is human, and the same is style, and style's blind pursuit is a utopian aesthetic daily consumption. A large number of beautiful women, handsome men as media advertising, make the product really occupy a part of the market, and people are will also be affected by the star effect when buying.

Visual effects are so widespread that they even dominate our consumer experience and judgment. In the modern consumption, the subject of consumption is no longer to get items, but achieve their own personal satisfaction and recognition of identity through consumption, which presents a broader opportunity for development in the field of graphic design. Secondly, the contemporary visual aesthetic tends to provide people with the experience of diversity and aesthetic experience. "Visual communication itself is the process that 
starts with people to convey the information through visual media to the artificial end."

This requires that the design should not only appeals to people's vision, but also communicates with people's emotions and the mind. Under the guidance of sensoryoriented, consumer-oriented culture trends entertainment, the prevailing style is "lone exception", which strives to design the constant and divergent surprising, in visual communications appealing to a large number of people sensory and emotional experience for the dissemination of results. In many print ads, the picture is not only a transfer of visual experience, but also can act on the human hearing, touch and even taste and smell so that the viewer feel the more diverse and exciting aesthetic experience.

Aesthetic trends of graphic design reflect the features of "visual consumption" and "eyeball economy". The dominant factors affecting the graphic designer has gone from concern for the material and technical level to the non-material aspects that concern value of the humanities. The use of computer virtual technology makes today's graphic design neither a manifestation of lasting value nor different with standard production under large industry, but the aesthetic manifestations of mass consumer. Contemporary design is different from the traditional design worshiping reason and logic, but a more personalized, diverse, pluralistic expression.

\section{CONCLUSIONS}

Good design is to incorporate the ethnic and regional characteristics into the design, and the cosmopolitanism of materials and technologies do not represent the cosmopolitanism of the design style and ideas. Domestic designers will present a common problem that they simplify ethnic and geographical characteristics, and only repeat the so-called national characteristics of symbols and practices in the design simply so that their design works seem nondescript and make people feel ridiculous. Many wellknown designers' works abroad contain very distinctive national culture color, but the way they behave in the works is their feelings of national culture and geographical features rather than simple imitation and repetition. Japan's famous graphic designer Tanaka Ikko mix modern design concepts and traditional Japanese art, and his works have distinct personalities: elegant, sober and simple, full of a certain color expressionism, simple and succinct language, mood with a beautiful form, showing unique ideas and practices in the fusion of Eastern and Western concepts of traditional aesthetics and cultural characteristics of the East and West.
His works show simple concise artistic temperament advocated by the Japanese national, and have a primitive vitality, clear pursuit of line and color's surface tension beyond the traditional Western sense of perspective and sketches and ease in blending contrasting colors peace. Thus, only the design built on a solid foundation of the national culture, will be recognized.

In order to obtain a unique style of development in the international premise, in addition to learning from outside, to dig local cultural resources, research-oriented aesthetic psychology and philosophy nation is an important thing for graphic design, because this is the root of the design and our culture. In our modern graphic design we should be based on the nation and face the whole world. Traditional inheritance is necessary and inevitable, and anything new is built on the basis of tradition. Now China's modern art and design are going to get out of its own way, and it is necessary to respect the uniqueness of ethnic art, reflect the aesthetic psychology of the nation, find advantages and unique artistic charm national tradition culture that other nations are not thinking, but also reflect the inherent spiritual pursuit of modern people. An art form produced and accommodated, it requires a specific historical and cultural background, including a national way of life, customs, ethical, aesthetic habits, which make up a potential deep cultural structure and are locked in the nation's mentalities and spirits. Therefore, traditional visual symbols with strong national flavor can really meet the aesthetic and spiritual needs of different ethnic audiences, and reflect the human care in designing work, and provide a lot of nutrition for the designer.

\section{References}

[1] Fang Kaizhu. Impact ink on graphic design [D]. Sichuan University, 2005.

[2] Zhu Yan. Graphic design aesthetic characteristics of the times of consciousness [D]. Hubei University of Technology, 2009.

[3] Zhuge Ruiqin. Understanding the psychological impact on women aesthetic modern bedroom interior design [D]. Northeast Forestry University, 2011.

[4] Zhang Yonggan. Effect "Modern Calligraphy" for graphic design [D]. Huaibei Normal University, 2011.

[5] Guo Xiaowei. modern graphic design creative and aesthetic research [D]. Northwestern University, 2012.

[6] Jiang Xiaowei. New media era of graphic design and performance characteristics of the paradigm [D]. Hunan Normal University, 2013. 